\title{
Performance of Inkjet-Printed Structures on Different Substrate Materials under High Humidity and Elevated Temperature Conditions
}

\author{
N.B. Palacios-Aguilera ${ }^{1}$, H.A. Visser ${ }^{2}$, L.D. Vargas-Llona ${ }^{2}$, U. Balda-Irurzun ${ }^{2}$, A. Sridhar ${ }^{2,3}$, R. Akkerman ${ }^{2}$, A. Bossche $^{1}$ \\ ${ }^{1}$ Electronic Instrumentation Laboratory, Delft University of Technology, Delft, the Netherlands \\ ${ }^{2}$ Production Technology Group, University of Twente, Enschede, the Netherlands \\ ${ }^{3}$ TNO-Holst Centre, Eindhoven, the Netherlands \\ n.b.palaciosaguilera@tudelft.nl
}

\begin{abstract}
Inkjet printing is widely being researched as enabling technology for printed electronics; however, there are scarce publications concerning the reliability of inkjet-printed structures on different substrates. The reliability of such structures under high humidity and high temperature conditions is treated in this work. To do so, the adhesion and resistivity of printed structures on PET, Rogers, PI and FR-4 materials are studied before and after a moisture resistance test. The samples present average resistivity values in the range of $12-106 \mu \Omega \cdot \mathrm{cm}$ and only one specimen of the Rogers sample fails the reliability test. The Rogers sample presents perfect adhesion characteristics, the adhesion can be improved for the rest of the samples, especially for the PI sample. The general performance of inkjet-printed structures on different substrate materials is good.
\end{abstract}

\section{Introduction}

Inkjet printing is widely being researched as enabling technology for printed electronics as well as organic electronics. The signs are indeed positive and indicate that inkjet printing is here to stay, and change the way electronic products are produced.

Examples of applications of this technology are inkjetprinted interconnection lines directly on Lithium ion batteries to save costs and materials by enabling the battery as the substrate for the whole system $[1,2]$, inkjet-printed interconnections to facilitate the integration of electronics and microfluidics [3] and the use of inkjet printing to fabricate antennas on PCB materials [4].

Because of the increased use of inkjet printing technology in a wide range of electronic applications, the reliability of inkjet-printed structures on different substrates, when subject to high humidity and elevated temperature conditions, needs to be studied in order to predict failures.

This work studies the reliability of inkjet-printed structures on different substrate materials under high humidity and temperature conditions. An ageing process is performed according to the military standard method 1004.7, also known as moisture resistance test, to determine the performance of such structures. The electrical characteristics, as well as the adhesion characteristics, are studied before and after the reliability test.

This work describes the materials used to prepare the samples. Furthermore, it explains how the samples are prepared and the experiment setup used to characterize them. It concludes presenting the results, conclusion and future work.

\section{Materials}

The substrate materials and the ink used to prepare the test specimens are described in this section.

A silver particle-based ink is used to print the specimens. Table 1 enlists de relevant properties of the ink according to the manufacturer. The name and brand of the ink have been consciously excluded.

Table 1. Properties of the silver ink.
\begin{tabular}{|c|c|}
\hline Property & Value \\
\hline Sintering temperature $\left({ }^{\circ} \mathrm{C}\right)$ & 125 \\
\hline Resistivity $(\mu \Omega \cdot \mathrm{cm})$ & $5-30$ \\
\hline Thickness $(\mu \mathrm{m})$ & $\sim 1^{\mathrm{a}}$ \\
\hline Metal content $(\%)$ & 20 \\
\hline${ }^{a}$ Measured with Dektak profiler
\end{tabular}

The substrate materials used to print the test structures are polyethylene terephthalate (PET), polyimide (PI), flame retardant 4 (FR-4) epoxy laminate and Rogers 4000.

The PET film used is manufactured by Sumitomo Electric Industries Ltd. The PI film is a film from DuPONT ${ }^{\mathrm{TM}}$ KAPTON ${ }^{\circledR}$ capable of maintaining its physical, electrical and mechanical properties at temperatures as high as $400{ }^{\circ} \mathrm{C}$ and as low as $-269^{\circ} \mathrm{C}$ [5]. The Rogers 4000 series substrate is a glass reinforced hydrocarbon/ceramic thermoset laminate (not polytetrafluoroethylene PTFE); this laminate is designed for high frequency applications as radio frequency identification (RFID) tags, cellular base station antennas or power amplifiers [6]; according to [4], electroless plating increases the continuity and thickness of printed structures, furthermore, no special treatments are required prior to perform electroless copper plating on this laminate. The FR-4 epoxy laminate used is Nelco N4000-6 FC, a high-Tg FR-4 epoxy laminate and prepreg system [7].

Table 2 shows the physical properties of the substrates. These properties are relevant to select a substrate-ink combination that allows printing reliable structures.

Table 2. Substrate materials' properties $[5,6,7,8,9,10,11]$

\begin{tabular}{|c|c|c|c|c|}
\hline & $P E T$ & $P I$ & Rogers & $F R-4$ \\
\hline $\begin{array}{c}\text { Glass transition } \\
\text { temperature } \mathrm{T}_{\mathrm{g}}\left({ }^{\circ} \mathrm{C}\right)\end{array}$ & $70-80$ & $\begin{array}{c}360- \\
410\end{array}$ & $>280$ & 175 \\
\hline $\begin{array}{c}\text { Coefficient of } \\
\text { thermal expansion } \\
\mathrm{CTE}\left(\mathrm{ppm} /{ }^{\circ} \mathrm{C}\right)\end{array}$ & $25-92$ & 20 & $\sim 14$ & $12-15$ \\
\hline $\begin{array}{c}\text { Relative } \\
\text { temperature index }\end{array}$ & $\begin{array}{c}100- \\
150\end{array}$ & $<240$ & $\begin{array}{c}105- \\
150\end{array}$ & 130 \\
\hline
\end{tabular}




\begin{tabular}{|c|c|c|c|c|}
\hline RTI $\left({ }^{\circ} \mathrm{C}\right)$ & & & & \\
\hline $\begin{array}{c}\text { Average roughness } \\
\mathrm{R}_{\mathrm{a}}(\mathrm{nm})\end{array}$ & $43.0^{\mathrm{a}}$ & $59.9^{\mathrm{a}}$ & $472.7^{\mathrm{a}}$ & $837.8^{\mathrm{a}}$ \\
\hline
\end{tabular}

The relative temperature index (RTI) is a property of particular interest that is a limitation when choosing the ink. The RTI indicates the maximum service temperature of a material where its mechanical, electrical and chemical properties will not be degraded [12, 13]; therefore, the curing temperature of the ink should not be higher than the RTI.

\section{Specimen Preparation}

The samples are printed using the ink described in table 1 and a drop-on-demand inkjet printer (Jetlab-4 from Microfab Technologies Inc., USA) with an $80 \mu \mathrm{m}$ diameter nozzle.

The temperature of the substrate holder is kept at $65{ }^{\circ} \mathrm{C}$ during the printing process.

An Oxygen plasma treatment at $100 \mathrm{~W}$ during $180 \mathrm{sec}$ is performed to the PET foil prior printing; this treatment is performed based in the results presented in [2]. The plasma treatment is necessary due to the hydrophobic characteristics of the PET surface.

Figure 1 shows one of the inkjet printed specimens with the test structure dimensions, the substrate used in this case is FR-4. The two $36 \mathrm{~mm}^{2}$ squares are used to perform the qualitative adhesion tests; the square in the left side is used for the qualitative adhesion test before the reliability tests (fresh), the square in the right side is used for the qualitative adhesion test after the ageing processes (aged). The cross structure is used to perform electrical measurements.

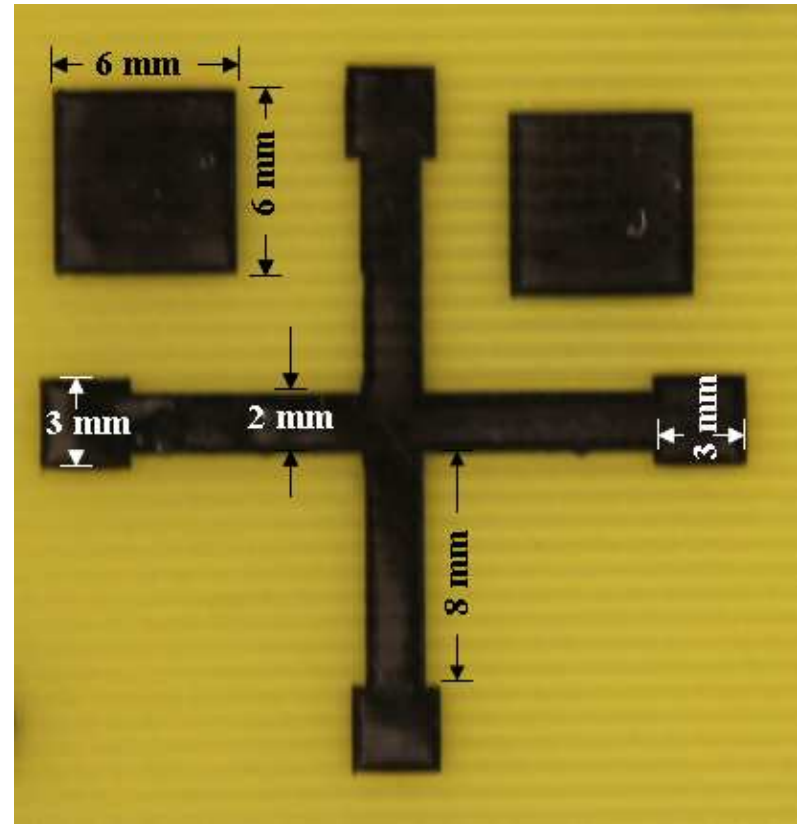

Fig. 1. Test specimen with the dimensions of the printed structure.

Three structures are printed per substrate material. After the structures are printed, the samples are cured at $125^{\circ} \mathrm{C}$ during 16 hours.

\section{Experiment Setup}

The experiment setup used to determine the mechanical and electrical characteristics of the structures is explained in this section.

In the case of mechanical characteristics, the adhesion is determined qualitatively using the Scotch-tape method described in $[1,2]$.

A Scotch tape is manually rolled in the squares printed for these purposes, and then the Scotch tape is peeled off. The silver ink adhered to the Scotch tape after peeling it off from the specimen is considered a failure in the adhesion of the ink to the substrate.

Furthermore, the adhesion of only fresh samples is determined quantitatively by measuring the lap shear tensile strength. To perform these measurements, a square is printed in the substrate material and using Araldite 2011, a brass metal strip is glued, as figure 2 shows, creating a bond area of $3 \times 3 \mathrm{~mm}^{2}$.

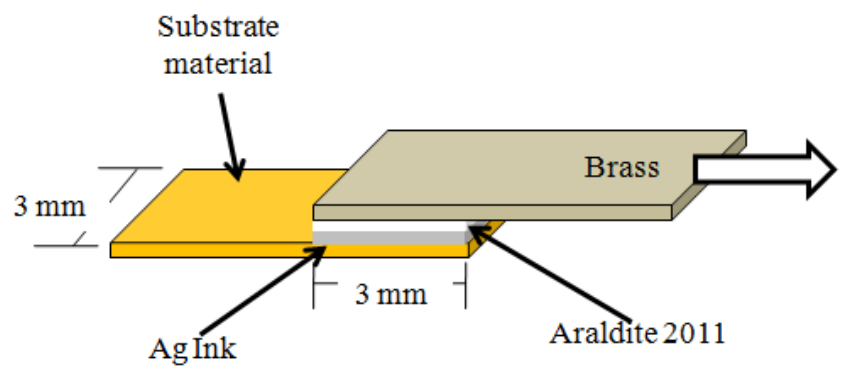

Fig. 2. Sample for quantitative adhesion measurements.

To quantitative measure the adhesion, the sample is placed in the Deben Microtest Module, a tension in the direction of the white arrow in figure 2 is applied, starting at $0 \mathrm{~N}$ until the sample fails or reaches the limit of the load cell $(200 \mathrm{~N})$. The results are given as extension (in $\mathrm{mm}$ ) and force (in $\mathrm{N}$ ) from which the strain-stress characteristics are obtained.

In the case of the electrical characteristics, the resistivity of the ink is determined using the Greek-cross method described in $[1,2,14,15,16]$. The current-voltage characteristics are obtained using a 4-point configuration and the resistivity value is derived from those two measured values. The thickness of the ink layer is necessary to obtain the resistivity value. The measured ink layer thickness $(t h)$ is rounded to $1 \mu \mathrm{m}$ and is measured with a Dektak profiler.

Figure 3 shows the setup used to measure the voltage and current. A current of $10 \mathrm{~mA}$ is passed from contact $\mathrm{A}$ to contact $\mathrm{B}$, the voltage is measured between contacts $\mathrm{C}$ and $\mathrm{D}$. Using the Ohm's law, the resistance is calculated.

Using equation 1 [14], the sheet resistance value is obtained.

$$
R s(\Omega / s q)=\frac{\pi R}{\ln 2}
$$




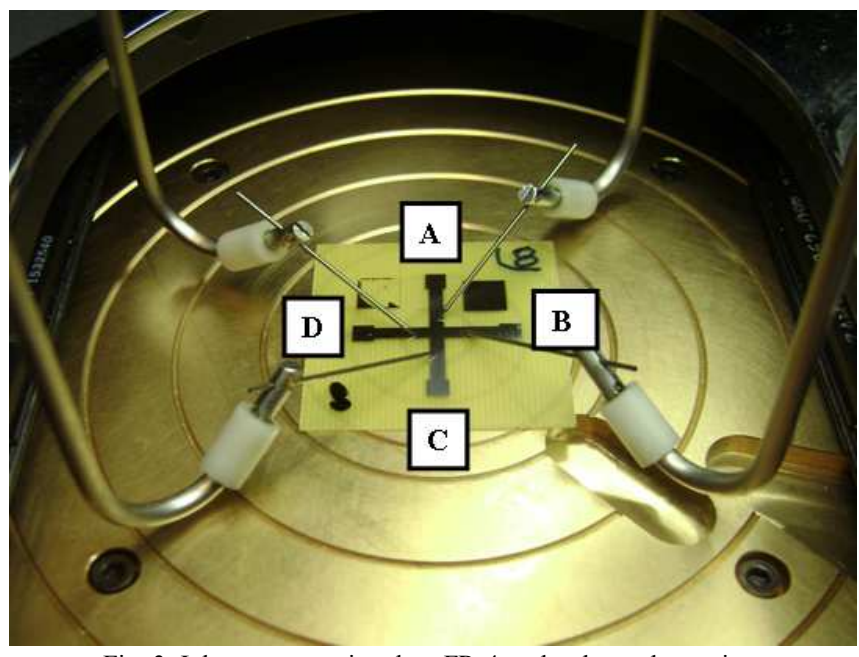

Fig. 3. Ink structure printed on FR-4 under the probe station.

The sheet resistance $\left(R_{s}\right)$ and the ink thickness $(t h)$ are multiplied to obtain the resistivity value. For a description of the equations used please refer to $[14,15,16]$.

The qualitative adhesion and resistivity are determined before and after the reliability test to determine the performance of the structures.

The reliability test performed to the samples is the moisture resistance test, performed according to the specifications of the military standard method 1004.7.

The electrical performance of the samples is considered good when the aged specimen resistivity changes less than 20 $\%$ respect to the non-tested specimen resistivity $[17,18]$.

\section{Results}

Figure 4 shows the average resistivity of three measured specimens for each substrate. The resistivity values of the different samples present values around $14 \mu \Omega \cdot \mathrm{cm}$, except the Rogers sample. The resistivity of bulk silver is $1.59 \mu \Omega \cdot \mathrm{cm}$.

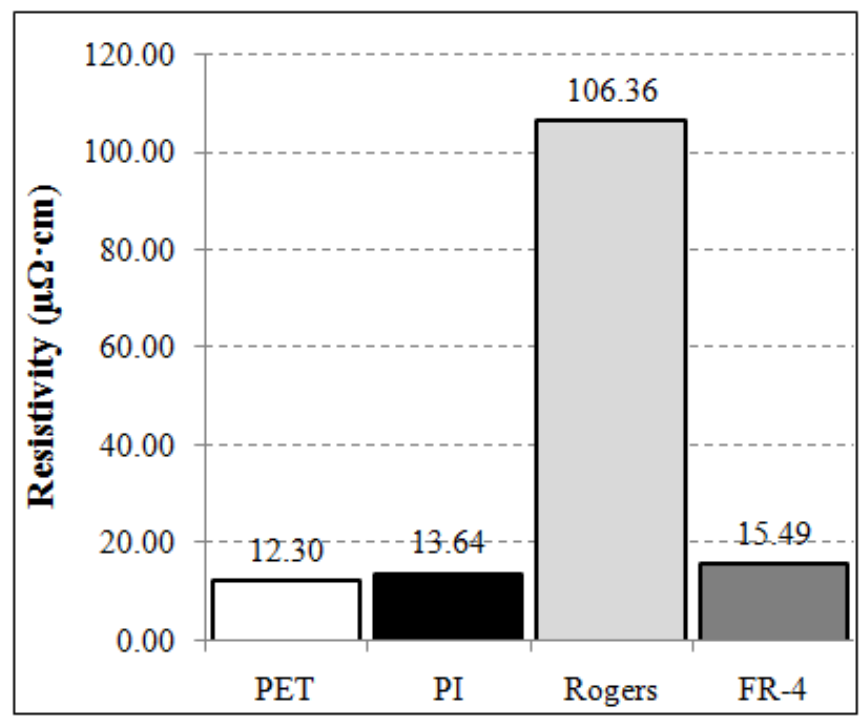

Fig. 4. Average resistivity of the printed structures in $\mu \Omega \cdot \mathrm{cm}$.

Furthermore, figure 5 shows the change of resistivity, in percentage, of the tested samples with respect to the fresh samples. The only sample failing the test is the Rogers sample; however, this is due to a failure in only one of the specimens. The percentages presented in figure 5 are an average of the resistivity change in percentage of three specimens per substrate material.

Figure 6 shows the standard deviation of the samples' resistivity. For most of the samples, the standard deviation is below $26 \%$ of the value of the average measured resistivity; however, for the Rogers sample, the standard deviation is $84 \%$ of the average measured resistivity, indicating there is a problem with the specimens.

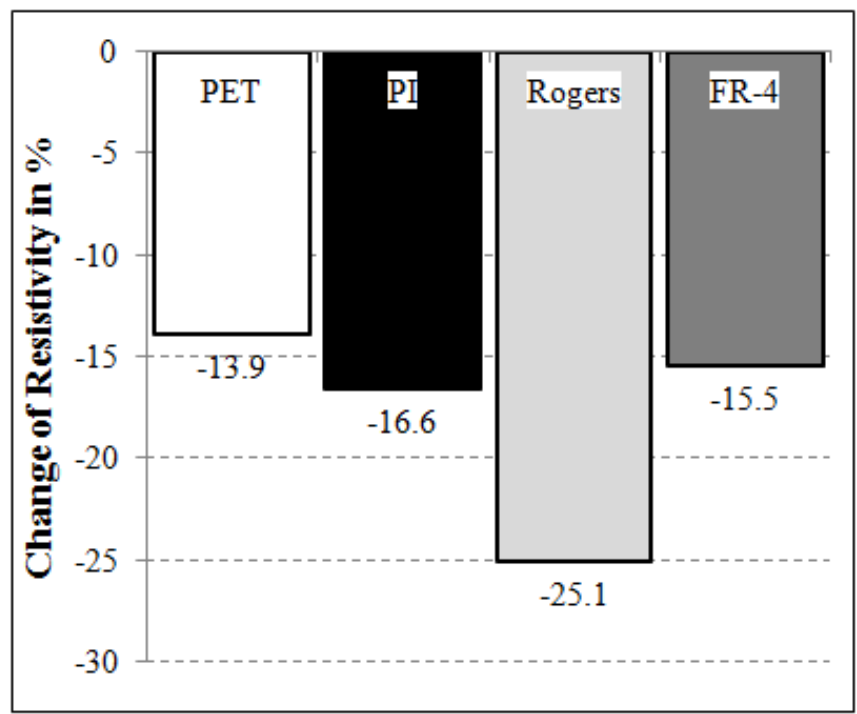

Fig. 5. Change of resistivity in percentage (\%) after the moisture resistance test.

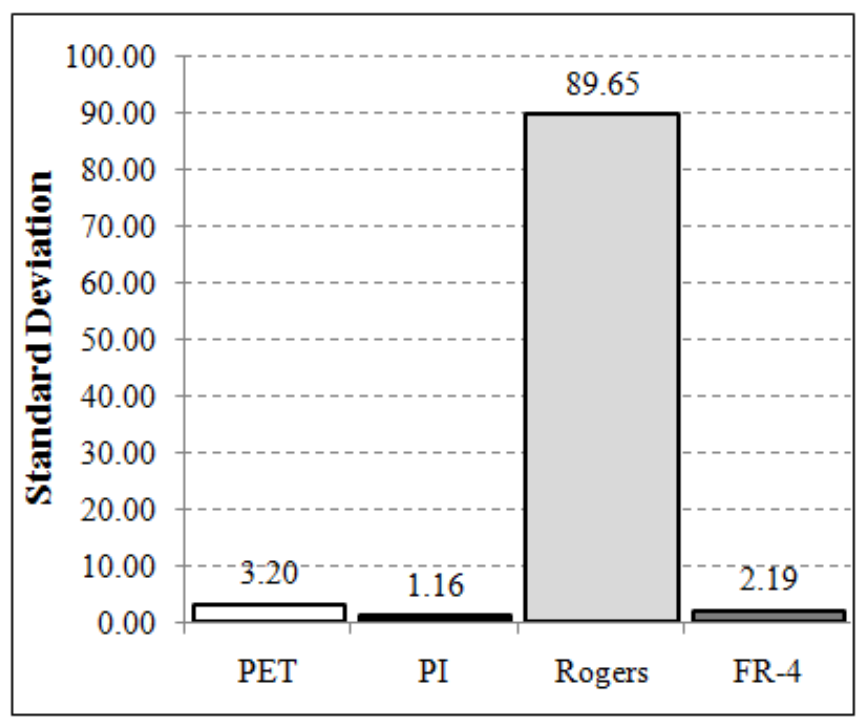

Fig. 6. Standard deviation of the printed structures.

The quantitative measured tensile strength of the fresh samples is $0.80 \mathrm{MPa}$ for the PI sample, $2.02 \mathrm{MPa}$ for the PET sample, and 19.43 MPa for the FR-4 sample. The failures are adhesive failures, that is to say, between the ink and the substrate material. The Rogers sample does not fail at a strength of $21.63 \mathrm{MPa}$. 
Figure 7 shows the results of the Scotch tape test. It shows the tape that is peeled off from the ink structure under the microscope. The white arrows point at failures, in other words, ink that is adhered to the Scotch tape, after is peeled off from the printed structures.

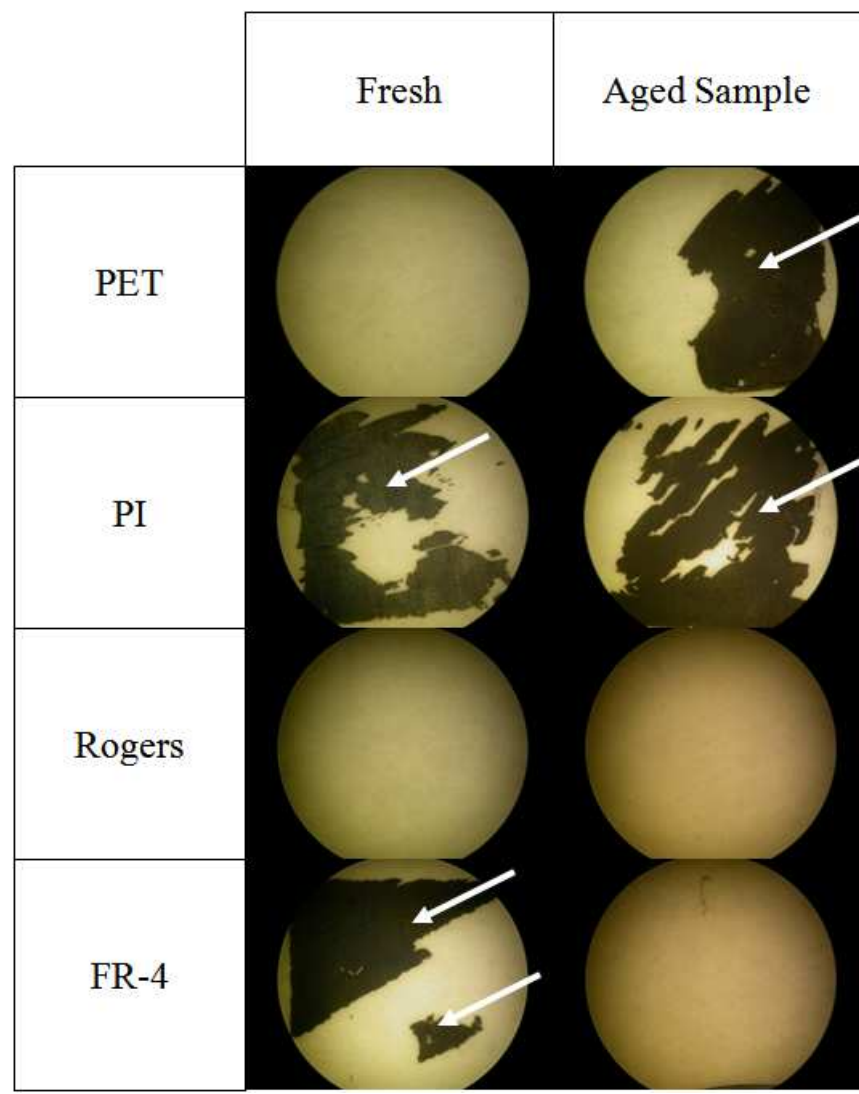

Fig. 7. Scotch-tape under the microscope after performing the adhesion test The white arrows point at the ink failures, in other words, the ink that is adhered to the Scotch-tape after peeling it off from the printed structure.

The stresses applied during the Scotch-tape test and the lap shear tensile strength test are different and therefore, it does not imply that the samples that present a weak adhesion in the Scotch-tape test have to present a weak adhesion in the quantitative measurement and the other way around.

All the samples present failures, except the Rogers sample. The microstructure of the samples is examined as well. Figure 8 shows the microstructure of the printed samples.

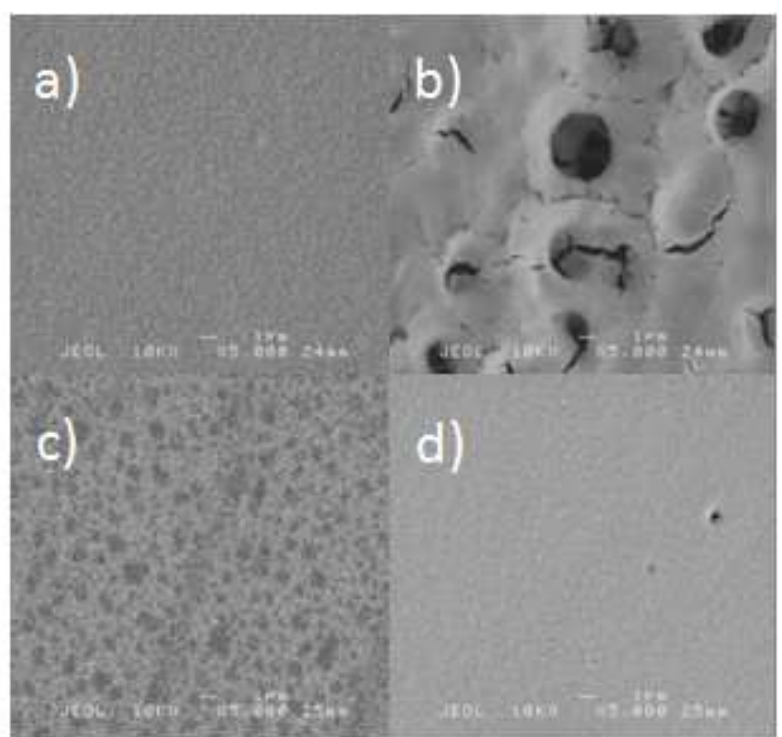

Fig. 8. Microstructure of the printed structures on a) PET, b) Rogers, c) FR-4, and d) PI at 5000x magnification.

Figure 8.b shows cracks around craters in the printed structure (Rogers sample). The craters in the ink are due to a copper layer in the back side of the Rogers material. To avoid such cracks and craters, the copper layer has to be removed prior printing; however, this does not improve the resistivity values, which might be due to the porosity of the substrate material and further research is recommended to study this more into depth.

\section{Conclusions}

The performance of the ink structures printed on different substrates is good; however, there is still margin to improve.

The adhesion of the ink is one of the factors to improve. The adhesion, in the case of the Rogers sample, is perfect without a plasma treatment. Furthermore, the adhesion of the PET sample should be improved to avoid failures when the specimens are subject to high humidity conditions. What concerns the PI and FR-4 substrates, the adhesion should be improved. The best approach to do this is studying which plasma treatment promotes the best adhesion characteristics between the substrates and the ink.

The electrical performance of the PET sample is the best, the rest of the samples present a good performance also; however, the resistivity values of the Rogers sample are high with respect to the pure silver resistivity.

The ink layer follows the surface morphology/topology and thus the microstructure is affected by the roughness of the substrate and the surface porosity.

In general, the ink presents good electrical performance when printed on different substrates; yet, when choosing other inks, the RTI should be considered a limitation for the ink curing temperature.

\section{Acknowledgments}

The authors thank Jeroen Bastemeijer, Jeff R. Mollinger and $\mathrm{Zu}-\mathrm{Yao}$ Chang for their valuable technical support as well as to the Delft Institute of Microsystems and Nanoelectronics (DIMES) staff members. 


\section{References}

1. Palacios Aguilera NB, Balda Irurzun U, Sridhar A, Bastemeijer J, Mollinger JR, Akkerman R, Zhou J, French PJ and Bossche A Shapeable Li-ion batteries as substrate: printed electronics reliability April 2011 Proceedings of International Conference on Electronics Packaging 2011 (Nara, Japan) pp 844-848

2. Palacios Aguilera NB, Balda Irurzun U, Sridhar A, Visser HA, Vargas Llona LD, Zhou J, Akkerman R, French PJ, Bossche A Reliable inkjet-printed interconnections on foil-type Li-ion batteries 2012 submitted.

3. Palacios Aguilera NB, Mokkapati VRSS, Visser HA, Bastemeijer J, Mollinger JR, Akkerman R, Bossche A Low-Cost Technology for the Integration of Micro- and Nanochips into Fluidic Systems on Printed Circuit Board: Fabrication Challenges. 2012 International Journal on Advances in Systems and Measurements vol 5 no 1 \& 2 pp. 11-21

4. Sridhar A 2010 An Inkjet Printing-Based Process Chain for Conductive Structures on PCB Materials University of Twente (Enschede, the Netherlands)

5. Dupont DuPont ${ }^{\mathrm{TM}}$ Kapton ${ }^{\circledR} H N$ polyimide film technical data sheet retrieved from http://www2.dupont.com/Kapton/en_US/assets/downloads/ pdf/HN_datasheet.pdf on 13th August 2012.

6. Rogers Corporation Advanced Circuit Materials $R O 4000(R)$ series high frequency circuit materials data sheet RO1.4000 retrieved from http://www.apcircuits.com/resources/information/ro4000ds 4.pdf on 13th August 2012.

7. Park Advanced Circuitry Materials Nelco ${ }^{\circledR}$ N4000-6 FC Nelco ${ }^{\circledR} \quad$ N4000-6 FC LD fast-cure, high-Tg multifunctional epoxy laminate \& prepreg retrieved from http://www.parkelectro.com/parkelectro/images/n40006fc.pdf on 13th August 2012.

8. Design News Extern UP thermoplastic polyimide retrieved from

http://www.designnews.com/document.asp?doc_id=22963 8 on 13th August 2012.

9. Dupont Branching and control manual with DuPont engineering polymers retrieved from http://plastics.dupont.com/plastics/pdflit/europe/markets/L 12118.pdf on 13th August 2012.

10. $\mathrm{P}+\mathrm{M}$ Services (R) Ltd. FR4 data sheet retrieved from http://www.p-m-services.co.uk/fr4_data_sheet.htm on 13th August 2012.

11. MathWeb Material Property Data Overview of materials for polyethylene terephthalate (PET) unreinforced retrieved

from http://www.matweb.com/search/DataSheet.aspx?bassnum= O3300\&group $=$ General\&ckck $=1$ on 13th August 2012.

12. UL Underwriters Laboratories Inc. Thermal aging program retrieved from http://www.ul.com/global/eng/pages/offerings/industries/c hemicals/plastics/testing/thermal/ on 13th August 2012.

13. Retrieved from http://www.elantas.com/fileadmin/ELANTAS/downloads/ beck/technical_reports/temperature index-en.pdf on 13th August 2012.

14. Enderling S, Brown CL, Smith S, Dicks MH, Stevenson JTM, Mitkova M, Kozicki M, Walton AJ Sheet resistance measurement of non-standard cleanroom materials using suspended Greek cross test structures 2006 IEEE Ttransactions on Semiconductor Manufacturing vol 19 no 1 pp 2-9

15. Walton AJ Microelectronic Test Structures 1997 Semicon '97 (Geneva, Switzerland)

16. van der Pauw LJ A method of measuring specific resistivity and Hall Effect of discs of arbitrary shape 1958 Philips Research Reports vol 13 no 1 pp 1-9

17. Liu J, Salmela O, Särkkä J, Morris JE, Tegehall PE and Andersson C 2011 Reliability of microtechnology interconnects, devices and systems Springer New York Dordrecht Heidelberg London

18. Parlex Corporation Polymer thick film - material performance and reliability retrieved from http://www.parlex.com/tech_library/PTFWhitePaper.pdf on 13th August 2012. 